\title{
LIFE OFFICE EXPENSES
}

\author{
BY R. C. WILKINSON \\ (Synopsis of a paper presented to the Society on 21 February 1989)
}

THE paper outlines the main problem areas generated by the document 'Life Assurance and Unit Trust Disclosure-The Regime for 1990' published by SIB in December 1988. It highlights the main topics which the appointed actuary, the actuarial profession and the industry have to consider in some depth to:

--help the regulators fully appreciate some of the practical problems;

- help formulate meaningful measures for with profits business;

-identify the areas in which further guidance is still required from the regulators;

—discuss the merits or otherwise of 'partial' disclosure which has now been proposed.

The Financial Services Act has created a new second tier of regulators who are more concerned with the marketing of investment products and protection of the policyholder in the case of life assurance, in addition to the existing regulation performed by the DTI. The paper traces the evolution of the disclosure rules and comments on the implications of different distribution channels.

The disclosure of charges and expenses is considered and it is suggested that the proposed basis of disclosure of actual charges is sensible and helps to bring down to one measure the very complicated subject of unit linked life policy charging structures. This together with quoted surrender values on a similar basis will give the policyholder much sensible informed advice. The requirement to disclose expenses brings to the fore the subject of their allocation, both to different funds within the life company and to different contracts. The proposal that expenses should be disclosed by means of a reduction in the yield to the policyholder is discussed, and some examples are given.

The paper concludes that the original aims laid down by Professor Gower do appear to be being achieved but at a very high cost to the industry and to the policyholder. The consumerist bodies have played a valuable part helping to formulate realistic disclosure to help protect the investor but they must admit that the majority of investors in life policies will be worse off as a result of these proposals. 